\title{
Cannibalism, cell survival, and endocrine resistance in breast cancer
}

\author{
Robert Clarke*
}

\begin{abstract}
Breast cancer cells often respond to an endocrine therapy by altering expression of specific estrogenresponsive genes and inducing autophagy, a cannibalistic lysosomal pathway. Autophagy eliminates damaged or other organelles, allowing the recovery of the energy stored in their macromolecules to attempt restoration of metabolic homeostasis. Induction of autophagy can result from activation of the unfolded protein response following metabolic stress, the final cell fate often being determined by the extent and duration of autophagy. A study by Gonzalez-Malerva and colleagues builds upon this extensive knowledge, adding HSPB8 to the list of altered genes associated with endocrine resistance in breast cancer and describing the ability of HSPB8 to regulate autophagy and confer tamoxifen resistance.
\end{abstract}

\section{Background}

Approximately $70 \%$ of newly diagnosed breast cancers express detectable levels of estrogen receptor alpha $(E R \alpha)$. Patients with these tumors generally receive an endocrine-based intervention, usually in the form of an aromatase inhibitor or antiestrogen. While these interventions are associated with a significant increase in overall survival [1], many ER $\alpha$-positive breast cancers recur.

Breast cancer cells often respond to endocrine therapies by altering the expression of a subset of estrogenresponsive and nonresponsive genes and inducing autophagy [2-7]. Autophagy is a lysosomal self-digestion pathway, where selected subcellular components are first segregated into double membrane-bound structures called autophagosomes [8]. Subsequent fusion with lysosomes forms autolysosomes, which enables the materials

*Correspondence: clarker@georgetown.edu

Department of Oncology, W405A Research Building, Georgetown University

Medical Center, 3970 Reservoir Road NW, Washington, DC 20057, USA sequestered therein to be digested by lysosomal hydrolases. Three primary forms of autophagy have been described: macroautophagy, microautophagy, and chaperonemediated autophagy. The comments in this viewpoint relate primarily to macroautophagy.

Autophagy can be prodeath or prosurvival and reflects an attempt by stressed cells to eliminate damaged or other organelles and recover the energy stored in their macromolecules to restore metabolic homeostasis. Autophagy can result from activation of the unfolded protein response (UPR) [9] in response to the metabolic stress of endocrine therapies [4]. In endocrine manipulated cells, prosurvival autophagy signaling is driven at least partly by UPR activation of the unconventional splicing of the estrogen-responsive XBP1 mRNA [3,10] and, downstream, increased expression of BCL2 family members including BCL2 and BCLW (BCL2L2) [11]. Prodeath signaling can involve induction of a caspasedependent apoptotic cell death (programmed cell death 1) [12] when there is adequate energy, and an autophagyassociated necrotic cell death that is probably energy independent [11]. An autophagic cell death, often referred to as programmed cell death 2 , also occurs. The extent of autophagy induced in response to stress may be controlled by the respective abilities of BCL2 and BCLW, and perhaps other BCL2 family members, to bind and sequester BECN1 [11], a key inducer of autophagy [8]. Regulation of the mammalian target of rapamycin (mTOR) by AKT also affects the induction of autophagy, and AKT is associated with UPR signaling [9].

An individual cell's fate can be determined by the extent and duration of autophagy. Prolonged exposure to a high level of autophagy can leave the cell with insufficient mitochondria and/or other organelles to survive (prodeath autophagy). Adequate recovery of energy by autophagy, with a sufficient remaining subcellular infrastructure, can allow the cell to survive (prosurvival autophagy) [13]. In the face of endocrine therapies, this survival is manifest as drug resistance.

\section{The article}

A recent study by Gonzalez-Malerva and colleagues used gene expression microarray analysis, and a functional 
genomic approach of overexpressing $>500$ full-length human kinase cDNAs, to study resistance in a series of MCF-7 cells with differing tamoxifen responses [14]. Thirty-one kinases were identified that both enhanced cell proliferation in the presence of 4-hydroxytamoxifen and were validated in at least four of six independent experiments. ERBB2 and IGF1R were among those genes that scored at least twice in these experiments, were differentially regulated in the microarray dataset, and are known to affect endocrine responsiveness [2]. Among the genes identified, the authors selected HSPB8 (heat shock $22 \mathrm{kDa}$ protein 8 ; E2-induced gene protein $1 ; \alpha$-crystallin $\mathrm{C}$ chain) for further evaluation because this gene gave one of the strongest responses in their primary assay, validated in five out of six screens, and was present in their microarray signature. A role for HSBP8 in tamoxifen resistance has not previously been reported.

Subsequent analyses in vitro showed that HSBP8 reduced the antiproliferative effects of 4-hydroxytamoxifen and blocked its ability to induce autophagy. The effects on autophagy were not mediated by chemical inhibition of the autophagy regulator mTOR, although the mTOR pathway was affected as assessed by changes in $\mathrm{p} 70 \mathrm{~S} 6 \mathrm{k}^{\mathrm{P}}$ and $4-\mathrm{EBP} 1^{\mathrm{P}}$. HSBP8 similarly affected these two proteins but independently of mTOR. An association of HSPB8 ( $\alpha$-crystallin $C$ chain) expression with a poor clinical outcome was described in one clinical gene expression dataset [14], an association previously reported for the $\alpha$-crystallin B chain protein [15]. Overall, the authors concluded that autophagy may be an important player in affecting tamoxifen sensitivity and noted that the mechanism of HSBP8 action requires further study.

\section{Viewpoint}

Activation of autophagy is clearly a key determinant of the nature of the response to antiestrogens in some breast cancer cells. In cells that are forced (and able) to activate an energy-dependent programmed cell death, it seems probable that autophagy provides both the energy and part of the cell destruction machinery. There are advantages to an orderly cell death that results in the release of at least partly digested cellular components, which may be less likely to induce the destructive inflammatory response associated with an apparently chaotic necrotic cell death. Adjacent cells in the microenvironment may be able to scavenge and more efficiently use released macromolecules to support their own attempt to evade the shared metabolic stress. For endocrine therapies, the prolonged duration of autophagy - even when prodeath is not immediately lethal - may explain why cell death is generally slow in vitro and why complete pathological responses are infrequent even among highly responsive ER $\alpha$-positive breast tumors. While the study by Gonzalez-Malerva and colleagues primarily addressed prodeath autophagy, a prosurvival autophagic adaptation to the nutrient deprivation present in poorly vascularized and/or endocrine-resistant tumors may explain the sometimes decades-long dormancy associated with breast cancer development and recurrence.

Gonzalez-Malerva and colleagues clearly add HSBP8 to the list of genes associated with endocrine resistance and autophagy [14]. How HSBP8 influences autophagy is unclear but the mechanism does not seem to involve mTOR. The researchers did not look in detail at other mechanisms such as those that affect BECN1 action, a pathway known to affect autophagy in endocrine responsiveness. The authors also implicate pathways independent of HSBP8 in antiestrogen resistance. Whether HSBP8 will be validated as an independent prognostic or predictive marker is not clear, since this was not seen in the independent dataset [14]. Nonetheless, HSBP8 is an interesting and important new addition to our understanding of cannibalistic autophagy signaling in endocrine resistance.

\section{Abbreviations}

ERa, estrogen receptor alpha; HSPB8, heat shock 22 kDa protein 8; mTOR, mammalian target of rapamycin; UPR, unfolded protein response.

\section{Competing interests}

The author declares that he has no competing interests.

Published: 12 August 2011

\section{References}

1. Early Breast Cancer Trialists' Collaborative Group: Tamoxifen for early breast cancer: an overview of the randomized trials. Lancet 1998, 351:1451-1467.

2. Musgrove EA, Sutherland RL: Biological determinants of endocrine resistance in breast cancer. Nat Rev Cancer 2009, 9:631-643.

3. Gu Z, Lee RY, Skaar TC, Bouker KB, Welch JN, Lu J, Liu A, Zhu Y, Davis N, Leonessa F, Brunner N, Wang Y, Clarke R: Association of interferon regulatory factor-1, nucleophosmin, nuclear factor- $\mathrm{KB}$, and cyclic AMP response element binding with acquired resistance to faslodex (ICI 182,780). Cancer Res 2002, 62:3428-3437

4. Clarke R, Shajahan AN, Riggins R, Cho Y, Crawford AC, Xuan J, Wang Y, Zwart A, Nehra N, Liu MC: Gene network signaling in hormone responsiveness modifies apoptosis and autophagy in breast cancer cells. J Steroid Biochem Mol Biol 2009, 114:8-20.

5. Inbal B, Bialik S, Sabanay I, Shani G, Kimchi A: DAP kinase and DRP-1 mediate membrane blebbing and the formation of autophagic vesicles during programmed cell death. J Cell Biol 2002, 157:455-468.

6. Bursch W, Ellinger A, Kienzl H, Torok L, Pandey S, Sikorska M, Walker R, Hermann RS: Active cell death induced by the anti-estrogens tamoxifen and ICI 164384 in human mammary carcinoma cells (MCF-7) in culture: the role of autophagy. Carcinogenesis 1996, 17:1595-1607.

7. Schoenlein PV, Periyasamy-Thandavan S, Samaddar JS, Jackson WH, Barrett JT: Autophagy facilitates the progression of ERa-positive breast cancer cells to antiestrogen resistance. Autophagy 2009, 5:400-403.

8. Mizushima N, Levine B, Cuervo AM, Klionsky DJ: Autophagy fights disease through cellular self-digestion. Nature 2008, 451:1069-1075.

9. Szegezdi E, Logue SE, Gorman AM, Samali A: Mediators of endoplasmic reticulum stress-induced apoptosis. EMBO Rep 2006, 7:880-885.

10. Gomez BP, Riggins R, Shajahan AN, Klimach U, Wang A, Crawford AC, Zhu Y Zwart A, Wang M, Clarke R: Human X-Box binding protein-1 confers both estrogen independence and antiestrogen resistance in breast cancer cell lines. FASEB J 2007, 21:4013-4027.

11. Crawford AC, Riggins RB, Shajahan AN, Zwart A, Clarke R: Co-inhibition of $B C L-W$ and $B C L 2$ restores antiestrogen sensitivity through BECN1 and 
promotes an autophagy-associated necrosis. PLOS ONE 2010, 5:e8604 doi:10.1371/journal.pone.0008604.

12. Nehra R, Riggins RB, Shajahan AN, Zwart A, Crawford AC, Clarke R: BCL2 and CASP8 regulation by NFKB differentially affect mitochondrial function and cell fate in antiestrogen sensitive and resistant breast cancer cells. FASEB J 2010, 24:2039-2054.

13. Clarke R, Shajahan AN, Wang Y, Tyson JJ, Riggins RB, Weiner LM, Baumann WT, Xuan J, Zhang B, Facey C, Aiyer H, Cook K, Hickman FE, Tavassoly I, Verdugo A, Chen C, Zwart A, Wärri A, Hilakivi-Clarke LA: Endoplasmic reticulum stress, the unfolded protein response, and gene network modeling in antiestrogen resistant breast cancer. Horm Mol Biol Clin Invest 2011, 5:35-44.

14. Gonzalez-Malerva L, Park J, Zou L, Hu Y, Moradpour Z, Pearlberg J, Sawyer J, Stevens $H$, Harlow E, LaBaer J: High-throughput ectopic expression screen for tamoxifen resistance identifies an atypical kinase that blocks autophagy. Proc Natl Acad Sci U S A 2011, 108:2058-2063.

15. Moyano JV, Evans JR, Chen F, Lu M, Werner ME, Yehiely F, Diaz LK, Turbin D, Karaca G, Wiley E, Nielsen TO, Perou CM, Cryns VL: aB-crystallin is a novel oncoprotein that predicts poor clinical outcome in breast cancer. J Clin Invest 2006, 116:261-270

\section{doi:10.1186/bcr2870}

Cite this article as: Clarke R: Cannibalism, cell survival, and endocrine resistance in breast cancer. Breast Cancer Research 2011, 13:311. 